\title{
Polymerization shrinkage stresses in different restorative techniques for non-carious cervical lesions
}

\author{
Ayla Macyelle de Oliveira Correia ${ }^{\mathrm{a}}$, João Paulo Mendes Tribst ${ }^{\mathrm{b}}$, Felipe de Souza Matos ${ }^{\mathrm{a}}$, \\ Jeffrey A. Platt ${ }^{\mathrm{c}}$, Taciana Marco Ferraz Caneppele ${ }^{\mathrm{a}}$, Alexandre Luiz Souto Borges ${ }^{\mathrm{b}, *}$

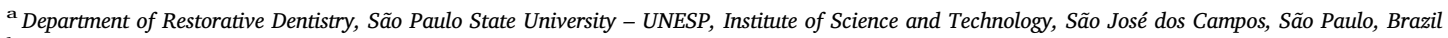 \\ b Department of Dental Materials and Prosthodontics, São Paulo State University - UNESP, Institute of Science and Technology, São José dos Campos, São Paulo, Brazil \\ ${ }^{\mathrm{c}}$ Department of Biomedical and Applied Sciences, Division of Dental Biomaterials, Indiana University School of Dentistry (IUSD), Indianapolis, IN, USA
}

\section{A R T I C L E I N F O}

\section{Keywords:}

Finite element analysis

Composite resins

Incremental technique

Polymerization

Dental stress analysis

Non carious cervical lesions

\begin{abstract}
A B S T R A C T
Objective: This study evaluated the effect of different restorative techniques for non-carious cervical lesions (NCCL) on polymerization shrinkage stress of resins using three-dimensional (3D) finite element analysis (FEA). Methods: 3D-models of a maxillary premolar with a NCCL restored with different filling techniques (bulk filling and incremental) were generated to be compared by nonlinear FEA. The bulk filling technique was used for groups B (NCCL restored with Filtek ${ }^{\mathrm{TM}}$ Bulk Fill) and C (Filtek ${ }^{\mathrm{TM}}$ Z350 XT). The incremental technique was subdivided according to mode of application: P (2 parallel increments of the Filtek ${ }^{\mathrm{TM}}$ Z350 XT), OI (2 oblique increments of the Filtek ${ }^{\mathrm{TM}}$ Z350 XT, with incisal first), OIV (2 oblique increments of the Filtek ${ }^{\mathrm{TM}}$ Z350 XT, with incisal first and increments with the same volume), OG (2 oblique increments of the Filtek ${ }^{\mathrm{TM}} \mathrm{Z350} \mathrm{XT}$, with gingival first) and OGV (2 oblique increments of the Filtek ${ }^{\mathrm{TM}} \mathrm{Z} 350 \mathrm{XT}$, with gingival first and increments with the same volume), resulting in 7 models. All materials were considered isotropic, elastic and linear. The results were expressed in maximum principal stress (MPS).

Results: The tension stress distribution was influenced by the restorative technique. The lowest stress concentration occurred in group B followed by OG, OGV, OI, OIV, P and C; the incisal interface was more affected than the gingival.

Conclusion: The restoration of NCCLs with bulk fill composite resulted in lower shrinkage stress in the gingival and incisal areas, followed by incremental techniques with the initial increment placed on the gingival wall. Clinical significance: The non-carious cervical lesions (NCCLs) restored with bulk fill composite have a more favorable biomechanical behavior.
\end{abstract}

\section{Introduction}

The marginal adaptation of composite resin restorations can be influenced by the type of adhesive system and factors related to the development of stress during the polymerization process of the restorative material [1-4]. The stress is influenced by factors such as elastic modulus [5], quantity of restorative material, cavity geometry [6], restorative technique, and light-curing protocol $[7,8]$. In addition, the composite resin polymerization shrinkage is an important source of interfacial stress [5].

Polymerization shrinkage produces stress at the tooth/restoration interface, which may result in the formation of marginal gaps, microleakage and micro-cracking that promote degradation and marginal staining $[7,9,10]$. This, in turn, may contribute to the development of postoperative sensitivity, secondary caries $[11,12]$ and pulpal inflammation resulting from the penetration of saliva, bacteria, and other irritating substances through the debonded interface [12]. The survival rate of these restorations can also be influenced by chemical degradation and attrition [13], stress concentration during mastication [14] and reduced adhesion to sclerotic dentin when present in NCCLs [15].

The development and improvement of restorative materials and filling techniques have been the primary approaches for reducing the stress caused by the resin composite polymerization shrinkage [16-20]. The incremental filling technique in oblique layers, with increments of less than $2 \mathrm{~mm}$, reduces polymerization stress through reduced cavity configuration factor (C-factor) and thickness of the resin composite [19].

The C-factor is defined as the ratio of bonded area to un-bonded

\footnotetext{
* Corresponding author at: Department of Dental Materials and Prosthodontics, São Paulo State University - UNESP, Institute of Science and Technology, Av. Eng. Francisco José Longo, 777 - Jardim São Dimas, São José dos Campos, SP, Brazil.

E-mail address: alexandre.borges@unesp.br (A.L.S. Borges).
} 
area of the dental cavity $[21,22]$. Its value is directly related to the stress developed at the interfacial bonding area. However, stresses generated by the material within a cavity depend not only on the Cfactor but also on the remaining dental structure and mass or volume of restorative material [23].

Non-carious cervical lesions (NCCLs), usually due to erosion, abrasion and/or abfraction of dental tissues [19], have a reduced C-factor. However, shrinkage stresses and microleakage are higher in restorations with larger diameters and depths and seem to be related to the volume of the restoration, but not to its C-factor [21]. Therefore, the geometry and cavity shape are the most critical factors to be considered $[6,24]$.

Techniques and materials have been developed to improve the longterm retention of cervical restorations. For large and/or deep restorations, incremental placement with oblique layers is recommended to decrease the effects of polymerization shrinkage and the thickness of a resin composite compared to other techniques [19]. However, this technique increases the possibility of incorporating voids between resin layers, as well as the time associated with placing and curing each layer of the material $[6,25]$.

Bulk-fill resin composites were introduced to replace the need for incremental layers [25,26]. These resins exhibit reduced volumetric contraction, lower shrinkage stress, and increased cure depth. This is possible due to the increased translucency and variations in the filler of these composites [26,27], which allows the placement of thicker increments. This prevents the formation of gaps and contamination between the layers of the material, providing more compact restorations $[28,29]$. These materials have the advantage of simplifying the restorative procedure and reducing the curing time compared to a conventional resin composite $[25,26]$.

The purpose of this study was to evaluate the influence of the restorative technique, using conventional or bulk-fill resin, on shrinkage stress in class $\mathrm{V}$ cavities of maxillary premolars using three-dimensional (3D) finite element analysis (FEA).

\section{Materials and methods}

\subsection{Elastic modulus}

The materials used in this study were two resin composites, Filtek ${ }^{\mathrm{TM}}$ Z350 XT and Filtek ${ }^{\mathrm{TM}}$ Bulk Fill. Their composition and manufacturer information are listed in Table 1.

Three bar-shaped specimens of each resin composite $(30 \times 3.5 \times 12 \mathrm{~mm})$ were used for analysis. The middle third of the sample was irradiated for $40 \mathrm{~s}$, after which the remaining thirds were irradiated for $40 \mathrm{~s}$ each. A LED light-curing unit (Radii cal, SDI, Australia) with an irradiance of $1100 \mathrm{~mW} / \mathrm{cm}^{2}$ was used. The irradiance was checked with a radiometer (L.E.D, Demetron; Kerr Corporation, Orange, CA, USA).

Composite elastic modulus was determined using the Sonelastic ${ }^{\circledast}$ (Atcp Engenharia Física, São Carlos, Brazil). Each sample was set in transverse vibration with a single-pulse excitation generated using small hammer driven by an electromagnet. While vibrating, the signal produced was captured by a microphone underneath the sample by a special signal analyzer. Fundamental frequency under flexure is
Table 2

Mechanical properties of the materials used in the tests.

\begin{tabular}{lllll}
\hline $\begin{array}{l}\text { Material/ } \\
\text { structure }\end{array}$ & $\begin{array}{l}\text { Elastic } \\
\text { Modulus } \\
\text { (GPa) }\end{array}$ & $\begin{array}{l}\text { Poisson's } \\
\text { Ratio }\end{array}$ & $\begin{array}{l}\text { aCoefficient of } \\
\text { Thermal Expansion, } \\
\text { mm/ } /{ }^{\circ} \text { C; Reference } \\
\text { Temperature: } 25^{\circ} \mathrm{C}\end{array}$ & Reference \\
\hline $\begin{array}{l}\text { Axson F16 } \\
\quad \text { Polyurethane }\end{array}$ & 3.6 & 0.30 & - & {$[31]$} \\
$\begin{array}{l}\text { Enamel } \\
\text { Dentin }\end{array}$ & 84.1 & 0.33 & - & {$[32]$} \\
$\begin{array}{l}\text { Pulp } \\
\text { Ligament }\end{array}$ & 18.6 & 0.31 & - & {$[33]$} \\
Filtek ${ }^{\mathrm{TM}}$ Z350 XT & 0.002 & 0.45 & - & {$[34]$} \\
Filtek $^{\mathrm{TM}}$ Bulk Fill & 13.45 & 0.45 & - & b35] \\
\end{tabular}

a Assumed value to represent the volumetric shrinkage necessary to thermal analogy simulation.

b Information obtained in laboratory tests described previously.

displayed on the screen of the apparatus. The elastic modulus values (GPa) and Poisson's Ratio obtained were used in the FEA (Table 2).

\subsection{Post-gel shrinkage measurements}

Ten samples were tested for each resin composite. Composite postgel shrinkage was determined using strain gages (KFGS-1-120-D16-11; KYOWA electronic instruments CO., Ltd., Tokyo, Japan, resistance $119.6 \pm 0.4 \% \Omega$; gauge length: $1 \mathrm{~mm}$; gauge factor: $2.08 \pm 1.0 \%$ ) [30]. Composite (diameter $=2.0 \mathrm{~mm}$ and height $=1.5 \mathrm{~mm}$ ) was placed on the measuring surface of biaxial strain gage and light-cured for $40 \mathrm{~s}$, using LED unit (Radii cal, SDI, Australia) with the light tip placed at $1 \mathrm{~mm}$ distance from the surface of the material. Variations of electrical resistance were converted into microstrain-rate units through an electrical signal conditioning apparatus (Model 5100B Scanner - System 5000 - Instruments Division Measurements Group, Inc. Raleigh, North Carolina, USA). Microstrain resultant from polymerization shrinkage was monitored for $5 \mathrm{~min}$ from the beginning of photoactivation in two perpendicular directions, due to the homogeneous and isotropic properties of the materials on a macro scale. The mean shrinkage strain was converted to a percentage and multiplied by three to express the material volumetric shrinkage. Thus, the coefficient of thermal expansion was determined and used to simulate polymerization shrinkage in the FEA (Table 2).

\subsection{Residual stress calculation: finite element analysis}

A previously validated 3D model simulating a maxillary premolar tooth was used [31]. The three-dimensional linear elastic analysis was performed based on anatomical geometric representations of dentine, pulp, enamel, periodontal ligament and alveolar bone (Fig. 1).

The Class V abfraction lesion, measuring $2.5 \mathrm{~mm}$ gingivo-occlusally, $5 \mathrm{~mm}$ mesiodistally and $1.5 \mathrm{~mm}$ in depth, was created, and respective restorations were simulated using different filling techniques (bulk filling and incremental). The bulk filling technique was used for groups B (NCCL restored with Filtek ${ }^{\mathrm{TM}}$ Bulk Fill) and C (NCCL restored with Filtek $^{\mathrm{TM}} \mathrm{Z} 350 \mathrm{XT}$ ). The incremental technique was subdivided according

Table 1

Technical information about the materials used in the study.

\begin{tabular}{|c|c|c|c|c|}
\hline Material & Manufacturer & Shade & Filler content & Resin matrix \\
\hline Filtek $^{\mathrm{TM}} \mathrm{Z} 350 \mathrm{XT}$ & 3M ESPE, St. Paul, MN, USA & A2 & $\begin{array}{l}78.5 \mathrm{wt} \% \text { ( } 59.5 \text { vol\%) } \\
\text { Silica, zirconia, aggregated zirconia/silica }\end{array}$ & Bis-GMA, UDMA, TEGDMA, Dimethacrylate \\
\hline Filtek $^{\mathrm{TM}}$ Bulk Fill & 3M ESPE, St. Paul, MN, USA & $\mathrm{A} 2$ & $\begin{array}{l}76.5 \mathrm{wt} \% \text { ( } 58.4 \text { vol\%) Silica, zirconia, ytterbium } \\
\text { trifluoride, aggregated zirconia/silica }\end{array}$ & AUDMA, AFM, UDMA, DDDMA, EDMAB \\
\hline
\end{tabular}




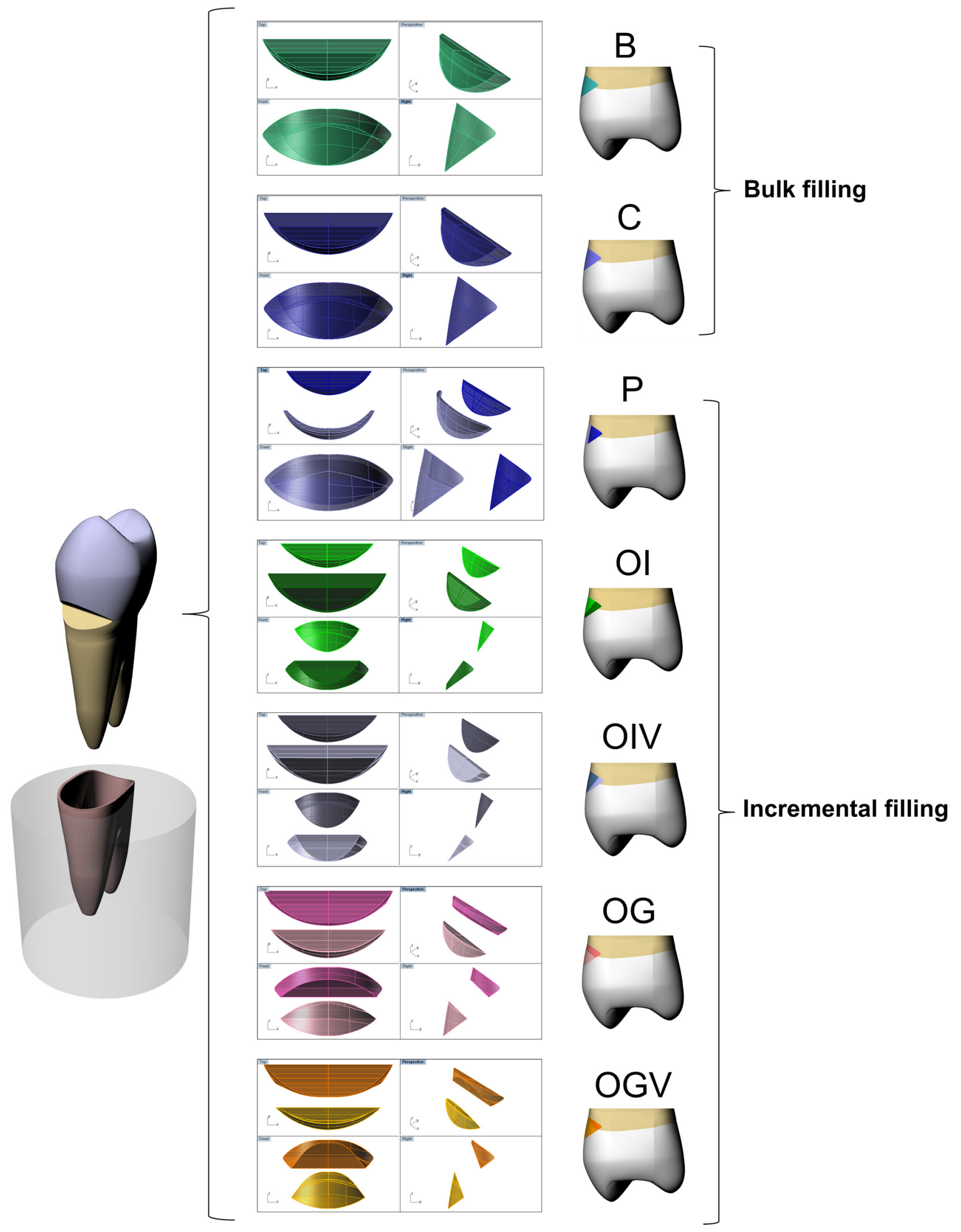

Fig. 1. A schematic illustration and four viewports of a maxillary premolar tooth and CAD models of the seven groups studied.

to mode of application: P (NCCL restored with 2 parallel increments of the Filtek ${ }^{\mathrm{TM}} \mathrm{Z} 350 \mathrm{XT}$ ), OI (NCCL restored with 2 oblique increments of the Filtek ${ }^{\mathrm{TM}}$ Z350 XT, with incisal first), OIV (NCCL restored with 2 oblique increments of the Filtek ${ }^{\mathrm{TM}} \mathrm{Z} 350 \mathrm{XT}$, with incisal first and increments with the same volume), OG (NCCL restored with 2 oblique increments of the Filtek ${ }^{\mathrm{TM}} \mathrm{Z} 350 \mathrm{XT}$, with gingival first) and OGV (NCCL 
Table 3

Details of Volume $\left(\mathrm{mm}^{3}\right)$ and Cavity C-factor for the different CAD models.

\begin{tabular}{llllc}
\hline Groups & $\begin{array}{l}\text { Volume } \\
\left(1^{\circ} \text { increment }\right)\end{array}$ & $\begin{array}{l}\text { Volume } \\
\left(2^{\circ} \text { increment }\right)\end{array}$ & Volume total & C-factor \\
\hline C & - & - & 5.92 & 1.43 \\
P & 3.57 & 2.35 & & \\
OI & 4.12 & 1.8 & & \\
OIV & 2.96 & 2.96 & & \\
OG & 3.55 & 2.37 & & \\
OGV & 2.96 & 2.96 & & \\
B & - & - &
\end{tabular}

restored with 2 oblique increments of the Filtek ${ }^{\mathrm{TM}} \mathrm{Z} 350 \mathrm{XT}$, with gingival first and increments with the same volume). Fig. 1 shows the seven groups analyzed in this work. All restorations were standardized with $5.92 \mathrm{~mm}^{3}$, and the values of C-factor obtained for each model are shown in Table 3.

The complete tooth structure and polyurethane resin were modeled with CAD (Computer Aided Design) Rhinoceros software (version 4.0 SR8, McNeel North America, Seattle, WA, USA) within the BioCad (CTI Campinas, Brazil) protocol. These CAD models were imported as STEP files into ANSYS software (ANSYS 17.2, ANSYS Inc, Houston, TX, USA), and the mesh was created with tetrahedral quadratic elements. Tests varying the size of elements were carried out until $10 \%$ of convergence of the results was reached, which determined that the ideal element size should be $0.3 \mathrm{~mm}$. The total number of elements was about 29,465 and 48,245 nodes. The polyurethane base was considered fixed in the three axes. All materials were considered homogeneous, linear, and isotropic, and their mechanical properties are summarized in Table 2.

The restoration-tooth interfaces in all the models were considered perfectly bonded. Polymerization shrinkage was simulated by thermal analogy [6]. The temperature was reduced by $1{ }^{\circ} \mathrm{C}$, and the coefficient of linear thermal expansion was entered.

A linear static structural analysis was performed to calculate the stress distribution in the cavity. The maximum principal stress (MPS) was chosen to analyze the stress concentration areas.

\section{Results}

The stress distribution for all models simulating different restorative techniques is presented in Fig. 2. The MPS values (MPa) and the frequency (\%) of data accumulated in the stress range were plotted on graphs (Figs. 3 and 4).

There was an influence in the residual tensile stress distribution as a function of the restorative technique. Compared to the other techniques, the bulk-fill technique resulted in a more homogeneous stress distribution at the tooth/restoration interface for Filtek ${ }^{\mathrm{TM}}$ Bulk Fill (B) and showed the lowest stress concentrations with peaks of smaller magnitude. The techniques used in OI and OIV promoted a substantial increase in tensile stress on the external surface of the tooth, particularly in the incisal/occlusal region, compared to models C, P, OG, and OGV (Fig. 2). In Fig. 4, the results show that in groups with a wider curve, higher stress values are found but at a lower frequency. Similar biomechanical behavior could be observed between models $\mathrm{C}$ and $\mathrm{P}$. When analyzing the effect of the volume of each increment, similar behaviors were verified between OG and OGV models, and between OI and OIV (Fig. 2).

\section{Discussion}

The present study used finite element analysis (FEA) to evaluate the influence of the filling technique on shrinkage stress in NCCLs. The results showed that the residual stress distribution depends on the restorative technique used and that the volume does not influence the stress generated by the polymerization shrinkage when compared to the final results obtained between the incremental filling techniques.

The stress generated by the polymerization shrinkage depends on the physical properties of the composites as well as their structural characteristics $[20,36]$. During the polymerization process, the volumetric contraction and solidification of restorative materials bound to hard tissues generate stress and deformation of the walls of the cavity [37] and are closely related to C-factor [22,36].

The elastic modulus of the materials also shows a positive correlation with the distribution of stress in the tooth [12,20,38]. An increase in filler volume content leads to reduced volumetric contraction $[36,38]$. On the other hand, a higher filler content results in rigid materials with high elastic modulus, providing higher tension for the same shrinkage values. The configuration of this study provided a controlled model that allowed comparing the behavior of materials in such circumstances, but results may vary under different test conditions, especially concerning C-factor and filling technique.

The filling techniques are also directly related to stress and stress distribution caused by polymerization shrinkage [20,36]. However, the potential of the incremental filling technique in reducing the stress at the adhesive interface is controversial [20,26,37,38]. In this study, model C showed concentrations of residual stress similar to model P. The increase in the number of increments, using a smaller volume of restorative material at each increment, was not able to reduce residual stress in model P (Fig. 2). Significant differences were also not found between these two techniques in gap formation and marginal microleakage [19]. Despite the results of the present study, the bulk fill technique (model $\mathrm{C}$ ) is not favorable to restore large wells with conventional composite resins, since it can negatively affect the polymerization and reduce the mechanical properties, so it is justified to use the incremental technique to promoted higher clinical longevity of the restoration [20,39].

Studies stated that the incremental filling technique in oblique layers reduces the thickness of the restorative material and, consequently, the volume of each increment, reducing the residual stress $[16,19,38]$. Higher stress areas were presented by OI and OIV models, particularly in the incisal/occlusal region (Fig. 4). The higher elastic modulus of dental enamel (84.1 GPa) [40] influenced the distribution of stress. For these reasons, it is possible to observe the similarity between the stress distribution pattern in OI and OIV (Figs. 2-4). Also, it is possible to observe in OI and OIV that even with the variation of the volume of each increment, the stress concentration was similar. Table 3 shows the volume of each increment for all models tested in the current study.

The restorative technique used in the OG model showed stress distribution similar to the OGV model which, among the incremental techniques, showed a better stress distribution pattern and presented as a good alternative when restoring NCCLs. In this case, less stress in the region of the incisal/occlusal enamel observed for this restorative technique can be explained by a difference in cavity geometry [6]. After placement of the first increment, the pulpal wall near the enamel margin became thinner and, therefore, more flexible. It may contribute to the reduction of stress during polymerization of the restorative material.

The results of this study show that the restored tooth with Filtek ${ }^{\mathrm{TM}}$ Bulk Fill presented lower stress concentration compared to the other restorative techniques (Figs. 2-4). Despite the filler content and similar elastic modulus of these resins (Tables 1 and 2), the best performance of Filtek $^{\mathrm{TM}}$ Bulk Fill can be attributed to features such as reduced volumetric shrinkage, low shrinkage stress and modulation of the polymerization reaction [12,25-27]. According to the manufacturer, high molecular weight aromatic dimethacrylate (AUDMA) decreases the number of reactive groups in the resin, while an additional methacrylate reduces the polymerization stress. Therefore, this material was expected to generate less tension, as was found. This restorative protocol may reduce the clinically undesirable effects of polymerization shrinkage, such as gaps, loss of restoration, postoperative sensitivity, 


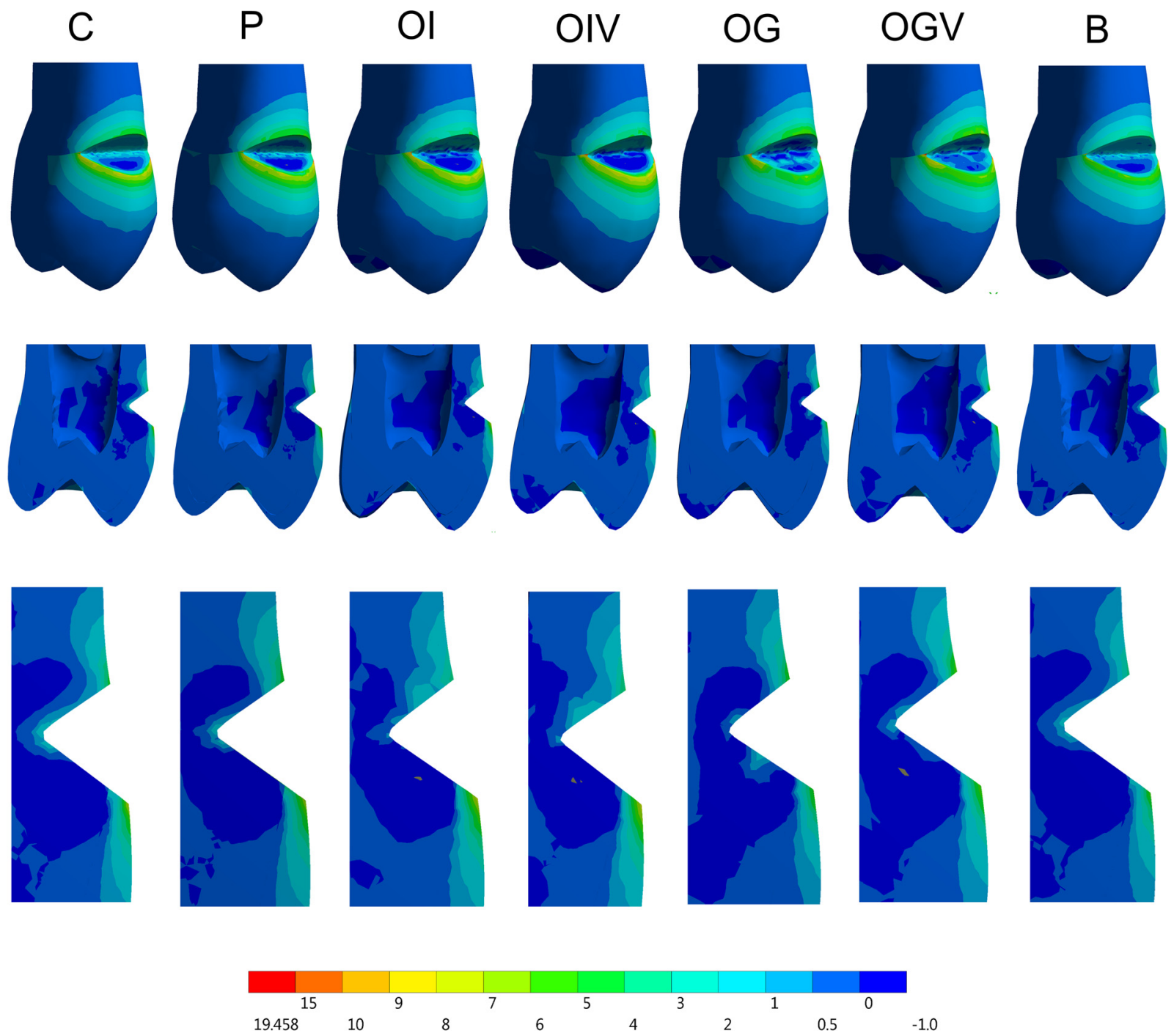

Fig. 2. Tensile stress (MPa) distribution in restored tooth according to the filling techniques.

His togram of Maximum Principal Stress (MPS)

Gingival area

30

Groups

25

$-\mathrm{B}$

$---\mathrm{C}$

----- OG

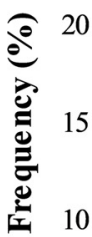

- $=\mathrm{OGV}$

$-\ldots$ OI

OIV

$---P$

Group Mean S.D. Min. Max.

\begin{tabular}{lllll}
\hline B & 2.51 & 1.12 & 0.21 & 4.19
\end{tabular}

\begin{tabular}{lllll} 
C & 3.57 & 1.29 & 0.32 & 5.49 \\
\hline
\end{tabular}

$\begin{array}{llllll}\text { OG } & 3.73 & 1.48 & 0.42 & 6.21\end{array}$

\begin{tabular}{lllll}
\hline OGV & 3.72 & 1.72 & 0.32 & 7.18 \\
\hline
\end{tabular}

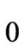

0

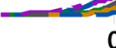

0

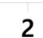

4

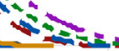

\begin{tabular}{ccccc}
\hline OIV & 3.02 & 1.09 & 0.29 & 4.79 \\
\hline$P$ & 3.80 & 1.26 & 0.37 & 5.60 \\
\hline
\end{tabular}

MPS (MPa)

Fig. 3. Distribution plot (MPa) of the maximum principal stress (MPS) in gingival area of cavity. 


\section{His togram of Maximum Principal Stress (MPS)}

Incisal area

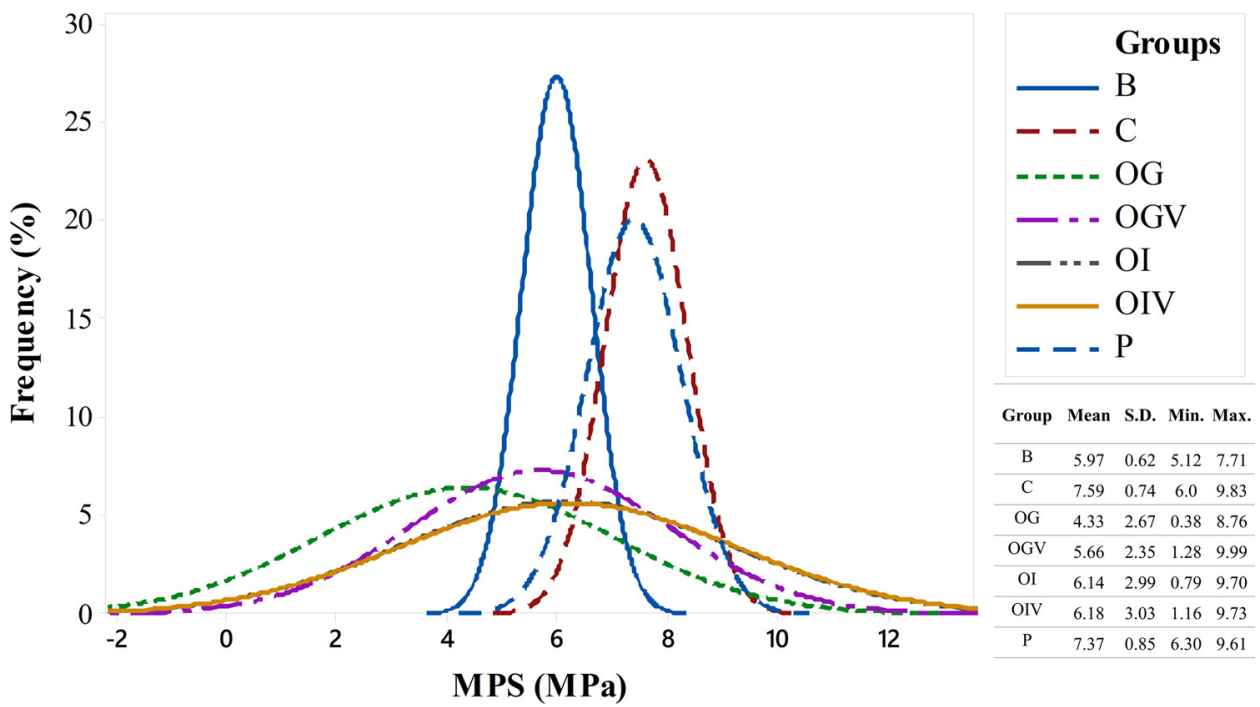

Fig. 4. Distribution plot (MPa) of the maximum principal stress (MPS) in the incisal area of the cavity.

microleakage, and marginal discoloration. Consequently, this may reduce the failure rates of the NCCLs and thus improve the general conditions for the clinical longevity of the restoration.

FEA allows the evaluation of different factors by isolating the variables of interest (e.g., area, volume, and geometry) and avoiding destructive damage [6]. However, the use of homogeneous and static models does not consider the consequences of the polymerization contraction [14]. Therefore, it is essential to validate these findings through other methodologies that take into account the restorative techniques evaluated in this study.

\section{Conclusions}

Within the limitations of this study, it was concluded that the filling technique influenced the polymerization stress distribution. The best stress distribution pattern was observed in the model restored with a bulk-fill technique and resin (model B). Among the incremental filling techniques, the OG and OGV models resulted in lower stresses with a similar distribution pattern.

\section{Conflict of interest}

The authors declare that there are no conflicts of interest.

\section{Funding}

This research did not receive any specific grant from funding agencies in the public, commercial, or not-for-profit sectors.

\section{References}

[1] I. Stojanac, M. Premovic, B. Ramic, M. Drobac, I. Stojsin, L. Petrovic, Noncarious cervical lesions restored with three different tooth-colored materials: two-year results, Oper. Dent. 38 (2013) 12-20.

[2] T. Fagundes, T. Barata, E. Bresciani, S. Santiago, E. Franco, J. Lauris, M. Navarro, Seven-year clinical performance of resin composite versus resin-modified glass ionomer restorations in noncarious cervical lesions, Oper. Dent. 39 (2014) 578-587.

[3] A.D. Loguercio, E.A. de Paula, V. Hass, I. Luque-Martinez, A. Reis, J. Perdigão, A new universal simplified adhesive: 36 -month randomized double-blind clinical trial, J. Dent. 43 (2015) 1083-1092.

[4] S. Kubo, H. Yokota, H. Yokota, Y. Hayashi, Three-year clinical evaluation of a flowable and a hybrid resin composite in non-carious cervical lesions, J. Dent. 38 (2010) 191-200.

[5] R.R. Braga, T. Yamamoto, K. Tyler, L.C. Boaro, J.L. Ferracane, M.V. Swain, A comparative study between crack analysis and a mechanical test for assessing the polymerization stress of restorative composites, Dent. Mater. 28 (2012) 632-641.

[6] A.L.S. Borges, A.B. Borges, T.A. Xavier, M.C. Bottino, J.A. Platt, Impact of quantity of resin, c-factor, and geometry on resin composite polymerization shrinkage stress in class V restorations, Oper. Dent. 39 (2014) 144-151.

[7] G.O. dos Santos, A.H. da Silva, J.G. Guimarães, A.A.L.E.M. Sampaio, E.M. da Silva, Analysis of gap formation at tooth-composite resin interface: effect of C-factor and light-curing protocol, J. Appl. Oral Sci. 15 (2007) 270-274.

[8] R.R. Braga, R.Y. Ballester, J.L. Ferracane, Factors involved in the development of polymerization shrinkage stress in resin-composites: a systematic review, Dent. Mater. 21 (2005) 962-970.

[9] I. Krejci, M. Planinic, M. Stavridakis, S. Bouillaguet, Resin composite shrinkage and marginal adaptation with different pulse-delay light curing protocols, Eur. J. Oral Sci. 113 (2005) 531-536.

[10] V.S.S. Gamarra, G.A. Borges, L.H.B. Júnior, A.M. Spohr, Marginal adaptation and microleakage of a bulk-fill composite resin photopolymerized with different techniques, Odontology 106 (2018) 56-63.

[11] J. Burgess, D. Cakir, Comparative properties of low-shrinkage composite resins, Compend. Contin. Educ. Dent. 31 (2010) 10-15.

[12] R.J.Y. Kim, Y.J. Kim, N.S. Choi, I.B. Lee, Polymerization shrinkage, modulus, and shrinkage stress related to tooth-restoration interfacial debonding in bulk-fill composites, J. Dent. 43 (2015) 430-439.

[13] R.E. Goldstein, S. Lamba, N.C. Lawson, P. Beck, R.A. Oster, J.O. Burgess, Microleakage around class V composite restorations after ultrasonic scaling and sonic toothbrushing around their margin, J. Esthet. Restor. Dent. 29 (2017) 41-48,

[14] A.C. Machado, C.J. Soares, B.R. Reis, A.A. Bicalho, L. Raposo, P.V. Soares, Stressstrain analysis of premolars with non-carious cervical lesions: influence of restorative material, loading direction and mechanical fatigue, Oper. Dent. 42 (2017) 253-265.

[15] R.M. Carvalho, A.P. Manso, S. Geraldeli, F.R. Tay, D.H. Pashley, Durability of bonds and clinical success of adhesive restorations, Dent. Mater. 28 (2012) 72-86.

[16] J. Park, J. Chang, J. Ferracane, I.B. Lee, How should composite be layered to reduce shrinkage stress: incremental or bulk filling? Dent. Mater. 24 (2008) 1501-1505.

[17] J.L. Ferracane, Resin composite - state of the art, Dent. Mater. 27 (2011) 29-38.

[18] Y. Kwon, J. Ferracane, I.B. Lee, Effect of layering methods, composite type, and flowable liner on the polymerization shrinkage stress of light cured composites, Dent. Mater. 28 (2012) 801-809.

[19] S. Kubo, H. Yokota, H. Yokota, Y. Hayashi, Challenges to the clinical placement and evaluation of adhesively-bonded, cervical composite restorations, Dent. Mater. 29 (2013) 10-27.

[20] A.A. Bicalho, A.D. Valdívia, B.C. Barreto, D. Tantbirojn, A. Versluis, C.J. Soares, Incremental filling technique and composite material-part II: shrinkage and shrinkage stresses, Oper. Dent. 39 (2014) e83-e92.

[21] R.R. Braga, L.C.C. Boaro, T. Kuroe, C.L.N. Azevedo, J.M. Singer, Influence of cavity dimensions and their derivatives (volume and "C" factor) on shrinkage stress development and microleakage of composite restorations, Dent. Mater. 22 (2006) 818-823.

[22] A.J. Feilzer, A.J. de Gee, C.L. Davidson, Setting stress in composite resin in relation to configuration of the restoration, J. Dent. Res. 66 (1987) 1636-1639.

[23] F.P. Rodrigues, N. Silikas, D.C. Watts, R.Y. Ballester, Finite element analysis of bonded model Class I "restorations" after shrinkage, Dent. Mater. 28 (2012) $123-132$

[24] E. Eliguzeloglu, O. Eraslan, H. Omurlu, G. Eskitascioglu, S. Belli, The effect of cavity shape and hybrid layer on the stress distribution of cervical composite restorations, 
Eur. J. Dent. 5 (2011) 180-185.

[25] B.M. Fronza, F.A. Rueggeberg, R.R. Braga, B. Mogilevych, L.E.S. Soares, A.A. Martin, G. Ambrosano, M. Giannini, Monomer conversion, microhardness, internal marginal adaptation, and shrinkage stress of bulk-fill resin composites, Dent. Mater. 31 (2015) 1542-1551.

[26] C.M.P. Rosatto, A.A. Bicalho, C. Veríssimo, G.F. Bragança, M.P. Rodrigues, D. Tantbirojn, A. Versluis, C.J. Soares, Mechanical properties, shrinkage stress, cuspal strain and fracture resistance of molars restored with bulk-fill composites and incremental filling technique, J. Dent. 43 (2015) 1519-1528.

[27] S. Bucuta, N. Ilie, Light transmittance and micro-mechanical properties of bulk fill vs. conventional resin based composites, Clin. Oral Investig. 18 (2014) 1991-2000.

[28] M. Par, O. Gamulin, D. Marovic, E. Klaric, Z. Tarle, Raman Spectroscopic assessment of degree of conversion of bulk-fill resin composites - changes at 24 hours post cure, Oper. Dent. 40 (2015) E92-E101.

[29] D. Papadogiannis, K. Tolidis, P. Gerasimou, R. Lakes, Y. Papadogiannis, Viscoelastic properties, creep behavior and degree of conversion of bulk fill composite resins, Dent. Mater. 31 (2015) 1533-1541.

[30] R.L. Sakaguchi, A. Versluis, W.H. Douglas, Analysis of strain gage method for measurement of post-gel shrinkage in resin composites, Dent. Mater. 13 (1997) 233-239.

[31] A.C. Souza, T.A. Xavier, J.A. Platt, A.L.S. Borges, Effect of base and inlay restorative material on the stress distribution and fracture resistance of weakened premolars, Oper. Dent. 40 (2015) E158-E166.

[32] A. Versluis, D. Tantbirojn, M.R. Pintado, R. DeLong, W.H. Douglas, Residual shrinkage stress distributions in molars after composite restoration, Dent. Mater. 20
(2004) 554-564.

[33] J.S. Rees, P.H. Jacobsen, J. Hickman, The elastic modulus of dentine determined by static and dynamic methods, Clin. Mater. 17 (1994) 11-15.

[34] C. Rubin, N. Krishnamurthy, E. Capilouto, H. Yi, Stress analysis of the human tooth using a three-dimensional finite element model, J. Dent. Res. 62 (1983) 82-86.

[35] S.V. Singh, M. Bhat, S. Gupta, D. Sharma, H. Satija, S. Sharma, Stress distribution of endodontically treated teeth with titanium alloy post and carbon fiber post with different alveolar bone height: a three-dimensional finite element analysis, Eur. J. Dent. 9 (2015) 428-432.

[36] H. El-Damanhoury, J. Platt, Polymerization shrinkage stress kinetics and related properties of bulk-fill resin composites, Oper. Dent. 39 (2014) 374-382.

[37] A. Versluis, W.H. Douglas, M. Cross, R.L. Sakaguchi, Does an incremental filling technique reduce polymerization shrinkage stresses? J. Dent. Res. 75 (1996) 871-878.

[38] C.J. Soares, A.A. Bicalho, D. Tantbirojn, A. Versluis, Polymerization shrinkage stresses in a premolar restored with different composite resins and different incremental techniques, J. Adhes. Dent. 15 (2013) 341-350.

[39] A.A. Bicalho, R.D. Pereira, R.F. Zanatta, S.D. Franco, D. Tantbirojn, A. Versluis, C.J. Soares, Incremental filling technique and composite material-part I: cuspa deformation, bond strength, and physical properties, Oper. Dent. 39 (2014) e71-e82.

[40] M.G. Roscoe, P.Y. Noritomi, V.R. Novais, C.J. Soares, Influence of alveolar bone loss, post type, and ferrule presence on the biomechanical behavior of endodontically treated maxillary canines: strain measurement and stress distribution, J. Prosthet. Dent. 110 (2013) 116-126. 